\title{
Negotiation Decision Support Systems: Analysing Negotiations Under the Conditions of Risk
}

\author{
Nipun Agarwal \\ Victoria University, Australia
}

\begin{abstract}
Negotiation Theory is a research area with emphasis from three different research streams being game theory, psychology and negotiation analysis. Recently, negotiation theory research has moved towards the combination of game theory and psychology negotiation theory models that could be called Integrated Negotiation Theory (INT). As, negotiations are often impacted by external factors, there is risk associated with achieving the expected outcomes. Prospect theory and Negotiation theory are combined in this paper to incorporate the risk associated within negotiations. Negotiation Decision Support Systems (NDSS) is an information technology tool using negotiation theory and artificial intelligence to assist disputants in a negotiation to obtain better negotiated outcomes than they can obtain otherwise. Due primarily to the limitations of bounded rationality and differing mental or physical state of the disputant. In the past, NDSS have primarily used game theory within their negotiation and decision making framework to assist disputants resolve negotiations, as game theory is easier to incorporate. This paper shows how INT and Risk Factors (Prospect Theory) can be incorporated into an NDSS to improve negotiation decision making.
\end{abstract}

\section{Keywords}

Negotiation, Negotiation Theory, Integrated Negotiation Theory, Negotiation Decision Support Systems, Prospect Theory

\section{Introduction}

Negotiation is used in every interaction we have with another human being in any instance, for example, where we purchase goods or services from someone, help a friend move a table from one room to another, help a stranger on the street or discuss a topic of mutual interest. However, due to numerous reasons negotiations don't go as well as we often plan and the negotiated outcomes don't meet our expectations. Resultantly, substantial research is being undertaken in the negotiation theory area that reviews negotiation from three different viewpoints: using game theory (from an economic viewpoint), psychology (from a cognitive, social or behavioural psychology viewpoint) and negotiation analysis (from a game theoretic and decision analysis viewpoint).

Negotiations are a series of two way concessions between individuals resulting in a compromise that will be acceptable to a majority of individuals comprising the negotiation. However, many negotiations are not closed to the outside world and external factors can have a minimal or significant impact on the negotiated outcomes. Therefore, this research will empirically review how negotiations under the conditions of risk work. Subsequently, as negotiation is such a critical part of human activity, information systems researchers decided to develop systems that would use the power of

Copyright (C) 2009 Victoria University. This document has been published as part of the Journal of Business Systems, Governance and Ethics in both online and print formats. Educational and non-profit institutions are granted a nonexclusive licence to utilise this document in whole or in part for personal or classroom use without fee, provided that correct attribution and citation are made and this copyright statement is reproduced. Any other usage is prohibited without the express permission of the publisher. computing to provide a tool to assist people in resolving negotiations more successfully. Resultantly, it can optimise and try to provide superior negotiated outcomes for each disputant in the negotiation. These specialised information systems used to support negotiations are called Negotiation Decision Support Systems (NDSS) or Negotiation Support Systems (NSS). 
This paper is structured according to the following sections:

1. Undertake a literature review to understand the research undertaken in the negotiation theory and prospect theory areas related to:
a. Negotiation Decision Support Systems (NDSS)
b. Game theory,
c. Negotiation analysis (game theory and decision analysis),
d. Psychological negotiation theory (cognitive, behavioural and social psychology),
e. Integrated negotiation theory (INT) that has come about with the convergence of including game theory and psychological negotiation theory within a single framework and
f. Prospect theory

2. Review how risk factors can be applied to negotiation theory and negotiation decision support systems.

3. Conclusion: a brief summary of the literature review and outcomes from this research.

Following the structure of this research provided above, the next sections will provide a Literature Review of Negotiation Theory.

\section{Negotiation Decision Support Systems \& Negotiation Theory}

Negotiation Decision Support Systems utilize Negotiation Theory within its underlying negotiation and decision framework. Resultantly, as per Raiffa (2005) the following three decision making frameworks are essential to negotiation theory and a list of NDSS applications that are based on these negotiation theories are:

1. Normative decision making that describe 'how a decision should be made in an ideal environment' (Raiffa et al. 2003), where game theoretic or optimization techniques are used to find solutions and examples of normative NDSS are SmartSettle (Thiessen et al. 2000) and INSPIRE (Kersten 1997),

2. Descriptive decision making states 'how decision makers act' and behavioral theories are utilized in this framework (Raiffa et al. 2002), here an example of a descriptive NDSS is WinSquared (2001), and

3. Prescriptive decision making is 'where decision makers see how a decision can be improved', while using normative and descriptive theories to form these suppositions, examples of a prescriptive NDSS is Family_Winner (Bellucci \& Zeleznikow 2004).

Moreover, Bellucci \& Zeleznikow (1996) and Bellucci (2004) state that Normative and Descriptive NDSS/Negotiation Theory models are backward looking and they don't provide disputants substantial insight into the decisions they need to make in the future. While, Prescriptive models are forward looking as they consider the ways that the negotiated outcomes can be improved rather than how a decision should have been made. Resultantly, Negotiation Theory researchers and practitioners have started reviewing concepts to develop more prescriptive models to improve the prescriptive power of negotiation models to provide superior solutions in order to assist in delivering more successful negotiations. Therefore, we will discuss Normative decision making theories in the realm of Game Theoretic Negotiation Theory and Negotiation Analysis in the following section. Thereafter, we will review Descriptive decision making theories in the Psychological Negotiation Theory area, which will lead us to the more Prescriptive decision making research that reviews recent work in the area of integrated Game Theoretic Psychological Negotiation Theory models. Integrated Game Theoretic Psychological Negotiation Theory models are more prescriptive because while researchers find Game Theoretic models Normative by themselves and Psychological Negotiation Theory models are seen as Descriptive. Nonetheless, these models provide significant information and analysis (i.e. game theoretic models provide information and model the interactive decision making patterns between 
disputants within a negotiation and psychological models provide information and insight into the individual cognitive, social and behavioural psychology aspects of disputants), thus when these two different type of negotiation theory models are integrated they provide two different facets of information which can collectively provide prescriptive solutions.

Additionally, while we review Negotiation Theory models we also need to understand and review the successful use of a NDSS that is an application of this integrated Negotiation Theory. Therefore, we understand that a negotiation is a complex process and numerous decisions are made by each disputant while analysing the decisions that would likely be made by their opponents in a negotiation. Often through the negotiation process it is hard to judge which decisions are correct or incorrect, further even harder sometimes to clearly confirm how successful a negotiation has been. So, it is difficult to figure out if an NDSS application has assisted in completing a negotiation successfully. In order to provide some understanding of how we could possibly calculate 'how successful a negotiation is', it could be possible to understand how happy the disputant is with their actual negotiated outcome, which could further be analysed to understand how much assistance the NDSS provided to improve those negotiated outcomes.

\section{Game Theoretic Negotiation Theory}

Game theory provides an insight into strategic human interaction in economic and social environments. Here, we initially review game theory concepts and its application in the negotiation theory research area.

Contemporary game theory has three forms: Zero-sum game theory (Von Neumann and Morgenstern 1944), co-operative game theory (Shapley 1953; Shapley 1977; Shapley and Shubik 1954; Luce and Raiffa 1957; Aumann and Drèze 1974; Myerson 1977) and non co-operative game theory (Nash 1951) that provide the initial basis for all research in the area of game theoretic negotiation theory (including bargaining and auction theory). Where, non co-operative game theory dominates the zero sum theory (as it is a system dynamic form of the latter). Also, von Neumann and Morgenstern (1944) and Nash $(1950 ; 1951 ; 1953)$ had suggested two game theory approaches to resolve bargaining problems: axiomatic or strategic. An axiomatic approach (sometimes called co-operative theory) provides a set of beneficial axioms implying a unique solution, while the strategic approach focuses on the outcomes of players in a non co-operative game modelling the bargaining process overtime. The axiomatic approach was dominant until 1980, but Rubenstein's (1982) solution of alternating players with discounting utility overtime provided the impetus for the strategic approach to gain momentum. Further, game theoretic aspect of negotiation theory that can be called strategic game theoretic negotiation theory has developed efficient and equilibrium proponents of fundamental welfare theorem by Arrow and Debreu (1954), Debreu (1959), Chaterjee and Samuelson (1983), Cramton (1992), Holmstrom and Myerson (1983), Satterwaite and Williams (1989) and Gresik (1995).

Where, Crawford (1982, p. 607) has stated that improving efficiency in bargaining outcomes does have substantial welfare gains. Some researchers, including Myerson (1979; 1984; 1985) have tried (and are still trying) to combine both the axiomatic and strategic approaches. Though, these game theoretic forms require complete information, but usually most bargaining situation only have incomplete information. Partially coinciding with this approach, Harsyani (1966, 1967, 1968a and 1968b) has provided a strategic game theoretic solution with incomplete information and Chaterjee and Samuelson (1983) have used Harsyani's theory to develop a static bargaining model with incomplete information with unknown reservation prices for the buyer and seller, while Rubenstein (1985) used this model using the opponent's discount utility factor to replace the unknown information. Additionally, Selten (1975) developed the sub-game perfect equilibrium theory, where Kreps and Wilson (1982) provided a sequential equilibrium with incomplete information utilizing statistical inference (Bayesian updating).

Morever, Raiffa, Richardson and Metcalfe (2002) have stated that game theory provides normative solutions (associated with interactive decision making) that aren't accurate enough (due to constraints), while cognitive and social psychology (behavioral) theories provide descriptive solutions (associated with analysis and implications of individual decision making). Nevertheless, it is 
highlighted by Luce and Raiffa (1967) that psychological theories though can't provide the interactive decision making relationship that can be provided by game theory, which is essential in a negotiation theory. Game theory lacks prescriptive power due to some specific reasons that are:

1. the possibility of existence of multiple plausible equilibrium solutions and no a priori method to choose between them to obtain one single optimal solution for any problem;

2. the constraint of players being completely rational can't work as totally rational negotiators (players) that doesn't exist in reality and some negotiators will probably make irrational decisions that can't be explained by game theory, thus Bazerman and Chugh (2004) define this problem as bounded awareness and bounded rationality of negotiators in a game (negotiation);

3. the elements, structures, priorities and rules aren't all common knowledge in a negotiation, further, the lack of such common knowledge can limit the prescriptive power of equilibrium oriented game analysis;

4. moreover, here Luce and Raiffa (1957) have also raised concerns of the limits to analyzing actual interactive conflict situations with game theory, as decisions can't incorporate infinite interrelationships between a player's (negotiator's) own actions and those of their opponents, thus some finite bounds need to be set for analyzing such games.

\section{Negotiation Analysis}

Raiffa (1982) introduced a new branch of negotiation theory called Negotiation Analysis that was based on the concepts of game theoretic negotiation theory and decision analysis (Multi Criteria Decision Analysis) and this research area has attained substantial momentum for other researchers to utilize it as a branch of Negotiation Theory. Raiffa (1982), Raiffa, Metcalfe and Richardson (2005), Bazerman, Neale, Valley, Zajac et al (1992); Thompson and Fox (2000) believe that Negotiation Analysis provides a more prescriptive approach to negotiation and its assists the negotiator in understanding their own behaviour, preferences and actions in comparison to those of their opponents (Bazerman 2005; Neale and Bazerman 1991), as well as the systematic ways in which decision makers deviate from rationality or optimality (Hastie and Dawes 2001; Kahneman and Tversky 1979; Tversky and Kahneman 1974; Trepel, Fox and Poldrack 2005). Even when negotiators are presumed to have bounded rationality (Simon 1957), they are still expected to make intelligent and rational decisions. Though, contrarily Bazerman (2005) states that often negotiators make inconsistent, inefficient and decisions based on normatively irrelevant information, due to the cognitive heuristics they apply to simplify core arguments. Nonetheless, while these heuristics are useful shortcuts to simplify decisions, they lead to predictable mistakes (Tversky and Kahneman 1974).

Further, Sebenius (1992) adds to the discussion on the background of Negotiation Analysis and states that while the primary roots of Negotiation Analysis are in decision analysis and game theory, this research area has had a really pragmatic prescriptive rather than normative view on resolving negotiation theory problems. Nonetheless, he also specifically identifies that game theory has been searching for the ultimate solution to predict outcomes of interaction between human beings, which would include bargaining, auctions, negotiations, market microstructure design and others. Thus, as game theory is still normative, though some progress has been made to provide prescriptive solutions (for example, Harsyani $(1967 ; 1968)$ and Shelling $(1960)$ ), even if no clear solution has been provided to this complex real world problem. However, he believes that game theory is especially useful in understanding repeated negotiations in well structured scenarios and for designing negotiation and bidding mechanisms supported through competitive dynamics within games. Thus, specialist applications of game theory, for example Weber (1985), Myerson (1991) and Siebe (1991) and Young (1991) are leading to more effective game theory application to the area of negotiation.

Nevertheless, the works by Shelling $(1960,1966)$ and McKersie (1965) were the first to be published incorporating aspects of Negotiation Analysis, adding game theoretic decision analysis understanding to explain negotiating or bargaining scenarios with informal game theoretic arguments. Negotiation Analysis was first formally introduced by Raiffa (1982) in the book, The Art and Science of 
Negotiation that formally defined the boundaries of the research area of Negotiation Analysis, which was followed by Sebenius' (1984) book, Negotiating the Law of the Sea: Lessons in the Art and Science of Reaching Agreement that build on the same basis of Negotiation Analysis provided by Raiffa (1982). Later, publications include Lax et al (1985), Lax and Sebenius (1986) and the latest book written by Raiffa, Metcalfe and Richardson (2005).

\section{Cognitive, Social and Behavioural Psychological Negotiation Theory}

Moreover, reviewing the psychological negotiation theory area we understand that it implicitly has three main research streams: cognitive, social and behavioural psychology that impact behaviour of disputants in a negotiation.

Bercovitch and Houston (2000) start by saying that there are three contextual dimensions that influence mediator behaviour, which are pre-existing factors (context of the conflict and identity of the parties), concurrent factors (identity of the mediator and actual mediation event) and background factors (the effect of mediation from previous mediation efforts). Further, they use a data set of 295 conflicts and using multivariate analysis they find that the conditions of the mediation environment and the identity of the conflicting parties are the most significant influences on the mediator's choice of strategy.

Kramer, Pommerenke and Newton (1993) suggest that negotiators are usually going to pursue equality division heuristics, especially when a common or social identity is salient to them and when they feel more accountable to the other parties in the negotiation. Where, social identity theory explains interpersonal behaviour in an individual's social group membership context (Hogg and Abrams 1988; Tajfel and Turner 1987; Turner 1987). Some support for the social identity theory in n-person conflicts has been provided by Dawes and Thaler (1988) and Kramer and Brewer (1984). Further, accountability is another aspect that activates self-presentation concerns because people seek approval from audience that observe their behaviour (Baumeister and Hutton 1987; Tetlock 1985), about appearing competent (Bond 1982; Ginzel, Kramer and Sutton 1992) and about appearing co-operative and fair (Greenberg 1990; Reis and Gruzen 1976), though in some situations they also demonstrate toughness and competitiveness (Carnevale, Pruitt and Button 1979; Sutton and Kramer 1990).

Negotiators also use decision heuristics that represent allocation rules that interdependent decision makers use to decide how resources should be divided between themselves (Allison and Messick 1990). These rules have been used to maximize relative gain, maximize individual gain, maximize joint gain or minimize difference between the negotiators (Kramer, Pommerenke and Newton 1993). Thus, Keenan and Wilson (1990) state that conceptual progress in bargaining theory requires an understanding of nonpecuniary motives that affect decisions during negotiations, which can be explained by social contextual analysis. Korobkin and Guthrie (2004) provide the heuristics that negotiators use to make judgments and choices that affect their outcomes, while negotiators can also use these factors to influence or change the choices of their competitors through anchoring (a negotiator can ask a higher price as an anchor in the first offer), availability (a negotiator can make available offers or supporting evidence that makes the opponents more likely to choose from the negotiator's offer), framing (a plaintiff could challenge the defendant to review the offer in light of the worst-case scenario rather than status quo to get the plaintiff to accept their lower offer) and contrast effects (causing an opponent to prefer an offering $\$ 30,000$ lump-sum, by providing an inferior offer of $\$ 10,000$ per year over three years or $\$ 30,000$ to a registered charity on behalf of the opponent).

\section{Integrated Game Theoretic Psychological Negotiation Theory}

We have gone through the substantial amount of research that has been undertaken by game theoretic and psychology researchers (Bazerman, Magoliozzi and Neale 1985; Kim, Bazerman, and Neale 1990; Weingart, Thompson, Bazerman, and Carroll 1990; Sondak and Bazerman 1991; Bazerman 2005), which discusses important negotiation issues some of which are advantages of integrative and distributive negotiations, BATNA, game theoretical models from Shelling (1960), Nash (1951), Harsyani $(1967,1968)$, bargaining theory, psychological factors that affect negotiations like 3D view 
of negotiations (Sebenius and Lax 2002), fair division of outcomes (Brams 1990; Brams and Taylor 1996), behavioral decision theory and negotiation analysis (Raiffa, Richardson and Metcalfe 2002), dynamic valuations in negotiations (Bendersky and Curhan 2003), type of negotiation (Berger, Kern and Thompson 2003), negotiating preferences (Bendersky and Curhan 2003), perceptual gaps (Cronin, Weingart, Cagan and Vogel 2002) and subjective reasoning in dynamic games (Feinberg 2002). These two groups of theories (game theoretic and psychological) provide a basis for the development of an integrated game theoretic psychological negotiation theory (integrated negotiation theory or INT) that is expected to provide prescriptive recommendations to improve negotiated outcomes.

As, negotiation theory researchers have been moving towards integrating game theoretic negotiation theory with psychological negotiation theory, we have seen two significant integrated negotiation theory models been developed by Neale and Northcroft (1991) and subsequently improved by Hausken (1997). Neale and Northcroft (1991) provide a conjoint behavioral and game theoretic negotiation theory model with Structural Influences (game theory factors - power, French and Raven 1959; Pfeffer 1981), deadline (time pressure reducing demands, aspirations and bluffing) and integrative potential (differential value assessment; non constant sum games: Thomas 1976) and Other People (agency theory factors - constituencies and third parties (Tirole 1988; Holstrom and Milgrom 1987; Holstrom and Myerson 1983)) as static factors and Cognition (planning, information processing, affect and individual differences) for each different player and Interaction Processes (influence tactics (reward, coercion, expertise, legitimacy and charisma: French and Raven 1959; information and communication power: Hausken 1997; persuasive tactics - assertion, rational argument and manipulation: Kipnis and Schmidt 1983) and communication tactics) as dynamic factors of their negotiation framework.

Hausken (1997) criticizes Neale and Northcroft's (1991) framework commenting that: first, observed choice behaviour is related to research perspective rather than game theory directly, as game theory is a symmetrically perspective rather than symmetrically descriptive research (Raiffa 1982, p. 20); second, that game theory has been described being unfit for descriptive research due to its extreme assumptions, instead recent development in game theory are slowly bringing prescriptive and descriptive research closer by relaxing these assumptions, for example, Harsyani $(1967 ; 1968)$ provides for incomplete information to be included, Taylor (1987) and Hausken (1996a; 1996b) incorporating social-moral utility involving maximized weighted functions for players, Shelling (1960) providing a strategic application to real world problems of disarmament, and others (like Rubenstein 1985; Selten 1975; Satterwaite and Williams 1989a; Fundenberg and Tirole 1983) who have provided solutions to simplify the restrictive game theoretic constraints further, where some of these latter research hasn't been identified by Neale and Northcroft (1991). Third, Neale and Northcroft (1991) identify Rapoport's (1959) article and remark how mathematising social interaction ignored the dynamics of negotiation interaction. Though, Rubenstein (1982), Binmore (1985), Camerer (1987) and others have provided further input into social and behavioral game theoretic solutions that haven't been considered by them. Fourth, Neale and Northcroft (1991) represent game theory as a static theory and cognitive/social psychological theories as dynamic in nature, however, Hausken (1997) states that this assumption is unfounded as game theory is dynamic as well. Further, Neale and Northcroft's (1991) framework for behavioural negotiation theory is: 


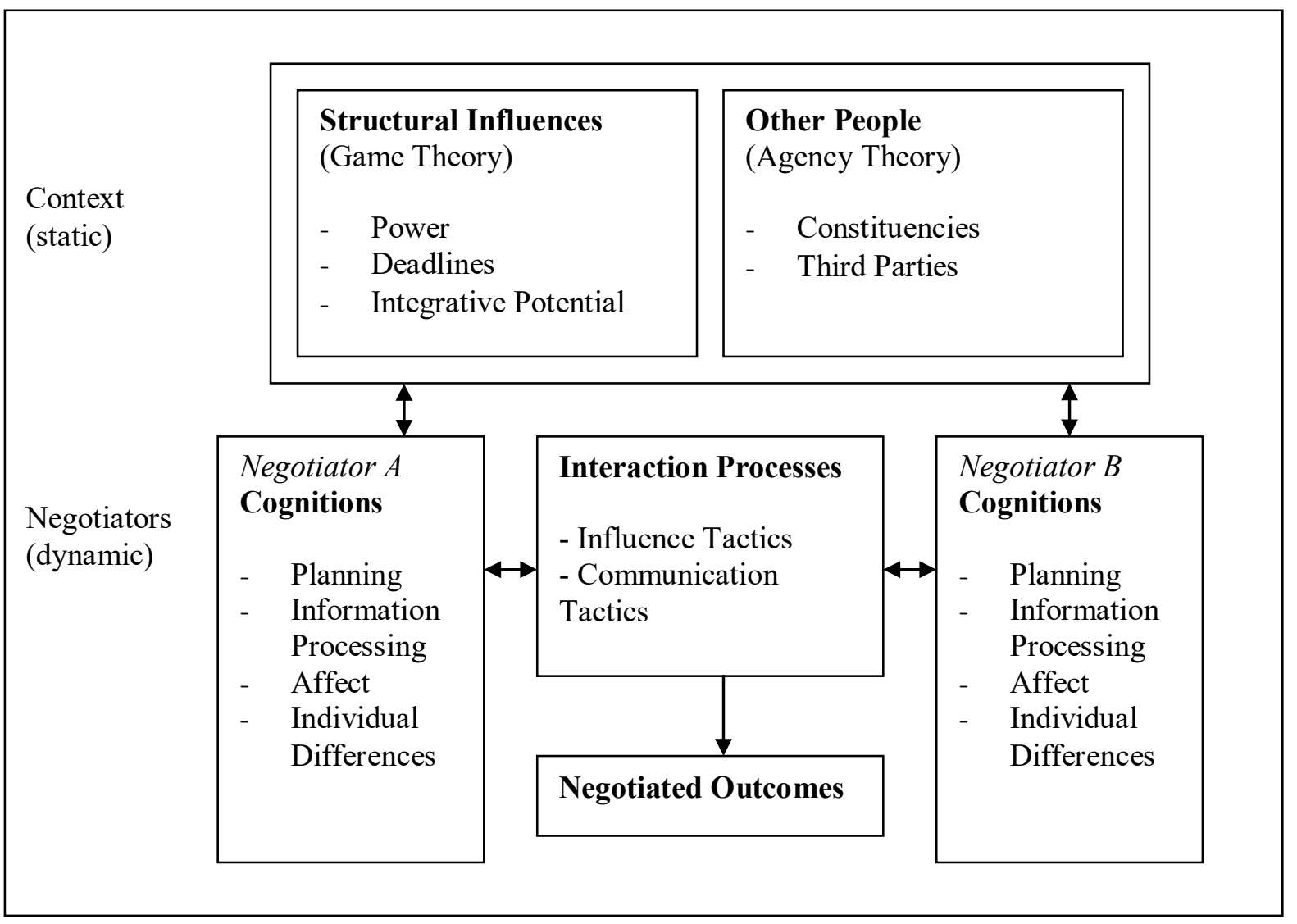

Figure 1. Framework for Behavioural Negotiation Theory (Neale and Northcroft 1991)

Hausken (1997) updates this Neale and Northcroft (1991) Framework for Behavioral Negotiation Theory model to provide an Integrated Game Theoretic and Behavioral Negotiation Theory from a game theoretic and a behavioural point of view, as follows:

\begin{tabular}{|c|}
\hline Static Structures: \\
\hline Game Theoretic: Payoff Structure \& Information Structure \\
\hline $\begin{array}{l}\text { Structural Influences (Social Psychological): Power, Deadlines, Integrative Potential and } \\
\text { other people (constituencies and third parties) }\end{array}$ \\
\hline Dynamic Structures: \\
\hline $\begin{array}{l}\text { Game Theoretic: Beliefs (subjective probability distribution over opponent's reservation } \\
\text { price) and Preferences (own reservation price) }\end{array}$ \\
\hline Cognitive: Planning, Information Processing, Affect and Individual Differences \\
\hline $\begin{array}{l}\text { Dynamic Structure (Game Theory): Extensive Form, Equilibrium Concepts, Time } \\
\text { Discount Factors and Attitude towards Risk; (Social Psychological): Interaction Processes } \\
\text { (Influence Tactics and Communication Tactics) }\end{array}$ \\
\hline
\end{tabular}

Provided Diagrammatically below: 


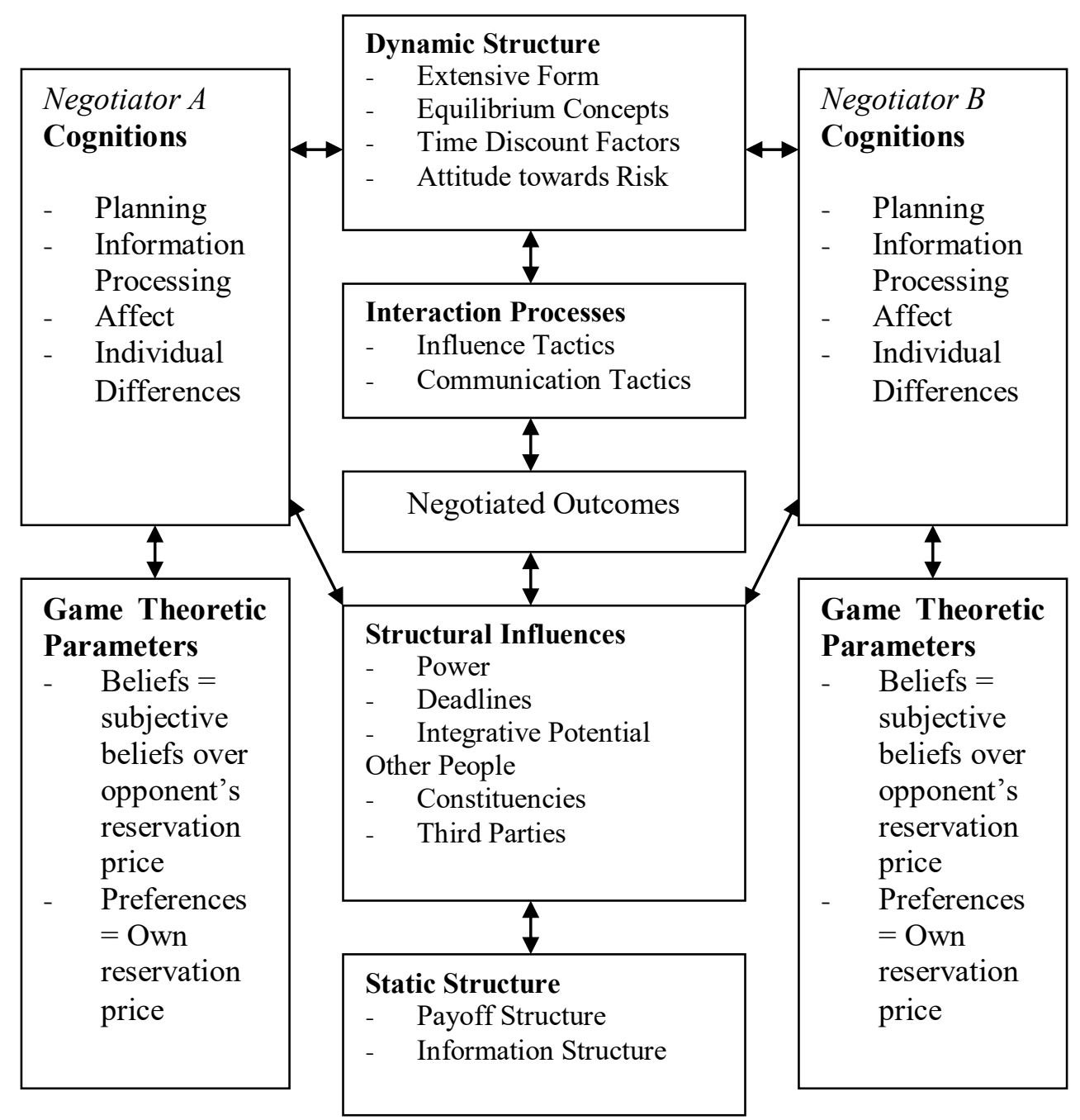

Figure 2. Integrated Behavioral and Strategic framework for Negotiation Theory from a Behavioral viewpoint (Hausken 1997)

While, Neal and Northcroft (1991) and Hausken (1997) have started a stream of research in integrated game theoretic psychological negotiation models, this research has a long way to go before significant breakthrough can be recognised through the development of more prescriptive and integrated models that link both game theory and psychological more intricately. However, both integrated negotiation theory models provided above by Neale and Northcroft (1991) and Hausken (1997) seems to have strong emphasis on either psychological theory as in Neale and Northcroft (1991) or game theoretic negotiation theory as in Hausken (1997). Therefore, a further rebalancing of the emphasis on both game theory and psychology is equally required to provide a well balanced prescriptive model. 


\begin{tabular}{|c|c|c|}
\hline $\begin{array}{l}\text { Negotiator A } \\
\text { Game Theoretic } \\
\text { Parameters } \\
\text { - Beliefs }= \\
\text { subjective } \\
\text { beliefs over } \\
\text { opponent's } \\
\text { reservation } \\
\text { price } \\
\text { Preferences } \\
=\text { Own } \\
\text { reservation } \\
\text { price }\end{array}$ & \begin{tabular}{ll} 
Interaction Processes \\
- & Influence Tactics \\
- & Communication Tactics \\
\multicolumn{2}{c}{ Dynamic Structure } \\
$-\quad$ Extensive Form \\
$-\quad$ Equilibrium Concepts \\
$-\quad$ Time Discount Factors \\
$-\quad$ Attitude towards Risk \\
Negotiated Outcomes
\end{tabular} & $\begin{array}{l}\text { Negotiator B } \\
\text { Game Theoretic } \\
\text { Parameters } \\
\text { - } \quad \text { Beliefs = } \\
\text { subjective } \\
\text { beliefs over } \\
\text { opponent's } \\
\text { reservation } \\
\text { price } \\
\text { Preferences } \\
\text { = Own } \\
\text { reservation } \\
\text { price }\end{array}$ \\
\hline I & $\begin{array}{l}\text { Static Structure } \\
-\quad \text { Payoff Structure }\end{array}$ & I \\
\hline $\begin{array}{ll}\text { Cognitions } \\
\begin{array}{ll} & \text { Planning } \\
- & \text { Information } \\
& \text { Processing } \\
- & \text { Affect } \\
- & \text { Individual } \\
& \text { Differences }\end{array}\end{array}$ & $\begin{array}{ll} & \\
& \\
\text { Structural Influences } \\
-\quad & \text { Power } \\
- & \text { Deadlines } \\
- & \text { Integrative Potential } \\
\text { Other People } \\
-\quad \text { Constituencies } \\
-\quad \text { Third Parties }\end{array}$ & $\begin{array}{l}\text { Cognitions } \\
\begin{array}{ll} & \text { Planning } \\
- & \text { Information } \\
& \text { Processing } \\
- & \text { Affect } \\
- & \text { Individual } \\
& \text { Differences }\end{array}\end{array}$ \\
\hline
\end{tabular}

Figure 3. Integrated Behavioral and Strategic framework for Negotiation Theory from a Game Theoretic viewpoint (Hausken 1997)

\section{Prospect Theory: Risk in Negotiation}

Von Neumann and Morgenstern's Expected Utility Theory (1944) provided the basis to analyze utility under the conditions of risk. Kahneman and Tversky (1979) provided the Prospect Theory that further improved on the Expected Utility Theory. There are four important principles provides by Prospect theory (Kahneman and Tversky 1979, 1992) over the Expected Utility Theory (Von Neumann and Morgenstern 1944):

1. Certainty Effect: people underweight probable outcomes against certain outcomes contributes to risk aversion to maintain sure gains, while risk seeking to reduce sure losses.

2. Isolation Effect: people discard options that are common - resulting in inconsistent preferences when the same option has been restructured in a different manner.

3. Value Function: is concave for gains and convex for losses, being steeper for losses than for gains - explains that people are more risk averse than risk taking.

4. Non-linear transformation: of the probability scale that over weights small probabilities and under weights moderate and high probabilities.

Quiggin (1982), Schmeidler (1989), Yaari (1987) and Weymark (1981) have provided a rankdependent or cumulative functional form of the prospect theory. Kahneman and Tversky (1992) 
incorporate these changes in their new form called the Cumulative Prospect Theory. They also state the five factors that should be included when viewing a rational theory of choice:

1. Framing effects: equivalent formulations of a choice problem should give rise to the same preference order (Arrow 1982). Contrarily, Kahneman and Tversky (1986) provide evidence that there is variance in preferences when options are framed differently.

2. Nonlinear Preferences: According to the Expectation principle in the Expected Utility theory the utility of a risky prospect is linear in outcome probabilities. However, Allias (1953) has observed nonlinear preferences exist in choices.

3. Source Dependence: Ellsberg (1961) observed that people will prefer to pick a ball from an urn that contains equal number of red \& green balls compared to an urn with unknown proportions of red \& green balls. People often prefer a bet on an event in their area of competence rather than just depend on chance (Heath and Tversky 1991).

4. Risk Seeking: people prefer a small probability of winning a large prize over the expected value of that prospect, while choosing a sure loss and a substantial probability of a larger loss.

5. Loss Aversion: A basic phenomena of choice under risk is that losses seem larger than gains (Kahneman and Tversky 1984; Tversky and Kahneman 1991).

An axiomisation of expected utility theory and cumulative prospect theory is provided by Wakker and Tversky (1993). This identifies for both models the situation that permits consistent inferences about the ordering of value preferences. It also reviews the major properties of the cumulative prospect theory's value function are diminishing sensitivity and loss aversion against the diminishing marginal utility in the expected utility theory. Prospect theory has specifically been useful in analyzing asset prices (Barberis, Huang and Santos 2001; Levy and Levy 2002), as prospect theory tries to understand the psychological behavior of people under the conditions of risk. Prospect theory has also been used in International Relations (Levy 1997; McDermott 1998). While, Fiegenbaum's experimental study (Fiegenbaum 1990) across 85 industries shows that organizations that did better than the average took three times lower risk than organizations which were below average.

Prospect Theory can also be used in analyzing risk associated in the decisions made by negotiators in a negotiation. Each negotiator makes their decision based on the actions taken by their opponents and each decision that a negotiator takes, will have costs/benefits and risk associated to it. The Hausken (1997) Game theoretic Viewpoint model (risk factors can be similarly included in the Hausken (1997) Behavioral Viewpoint model) can be modified to include risk in negotiator decision making (see Figure 4 below). 


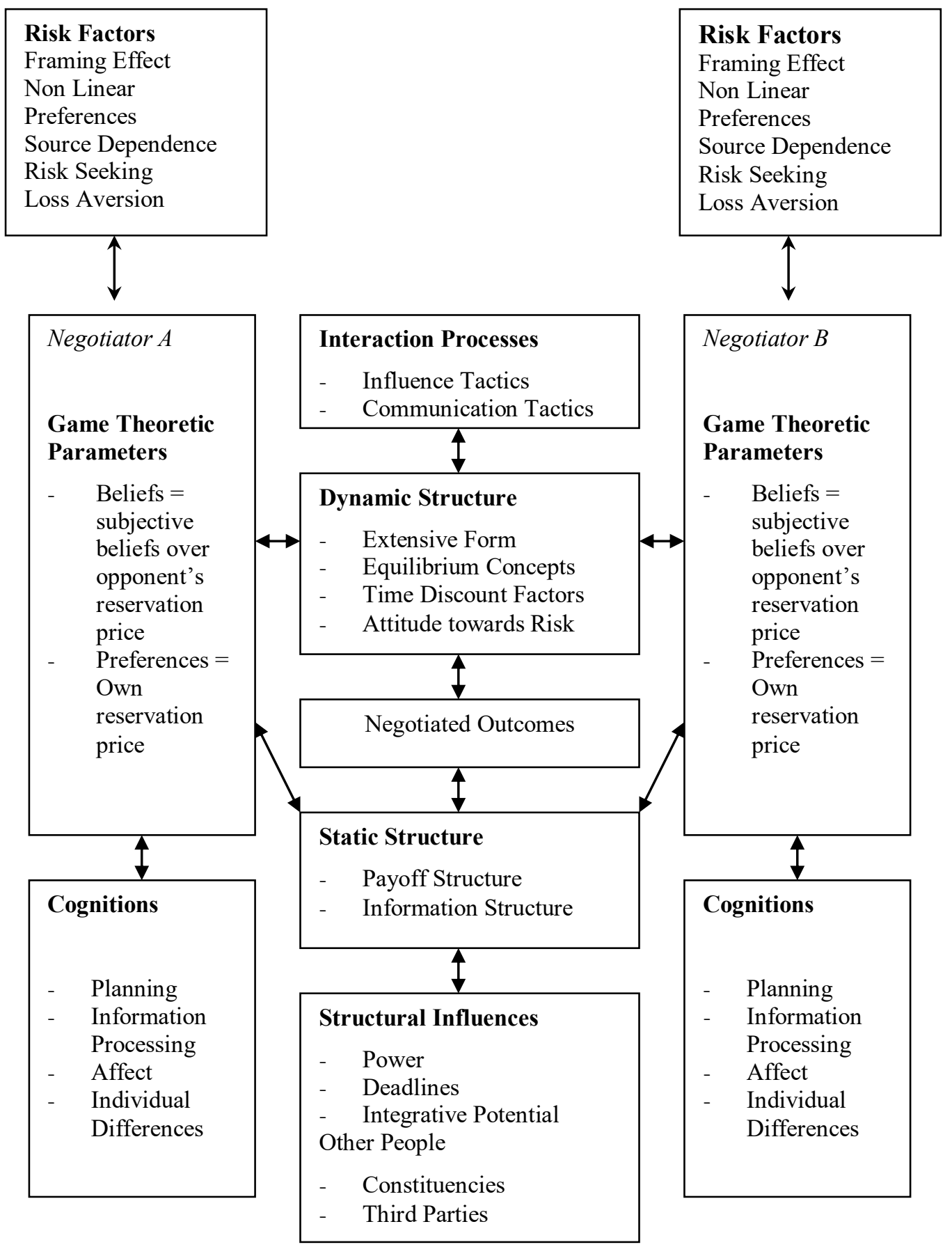

Figure 4. Integrated Behavioral and Strategic framework for Negotiation Theory from a Game Theoretic viewpoint (Hausken 1997) including Risk Factors

\section{Implementing Risk in an NDSS Negotiation Framework}

The Hausken (1997) Game Theoretic Viewpoint model has been modified to include Risk Factors (Framing Effect, Non Linear Preferences, Source Dependence, Risk Seeking and Loss Aversion). These Risk Factors will help assess the risk associated within the decisions made by each negotiator in a negotiation. These Risk Factors will have the following impact on a negotiator's decision pattern:

1. Framing Effects - Depending on how the question is framed (negatively or positively), the negotiator will either see it as a loss (negatively framed question) or as a gain (positively framed question). 
2. Non Linear Preferences - People have non linear preferences, where they prefer gains over losses. Therefore, they try to avoid losses and make gains.

3. Source Dependence - People put emphasis on the source of the information. If they can or cannot rely on the source of the information.

4. Risk Seeking - In general, people are risk seeking for losses - they will take risk to avoid losses and are risk averse for gains - they will avoid risk to conserve their gains.

5. Loss Aversion - Normally, people would not like to make losses, therefore they are loss averse. If they have losses then they will take risk to avoid those losses.

While, these Risk Factors can explain decision patterns of negotiators. We intend to include them in the negotiation framework of a Negotiation Decision Support System (NDSS). At present, NDSS negotiation frameworks mainly incorporate game theoretic models. The intent of this paper was to show that negotiation theory practitioners and theorists have started moving towards conjoining game theoretic and psychological models. This paper identified two models by Neale and Northcroft (1991) and Hausken (1997). Further, it also showed how Risk Factors could be included in the Hausken (1997) framework. Providing a cojoined game theoretic psychological negotiation theory model under the conditions of risk, this paper calls it an Integrated Negotiation Theory (INT) model under the conditions of risk (also, called an INTR model). This paper recommends that such an INTR model be used to better assess negotiator decisions, allowing the NDSS to assist in providing better negotiated outcomes for these negotiators.

\section{Conclusions}

In conclusion, this paper reviews Negotiation Decision Support Systems (NDSS), negotiation theory and prospect theory to understand how a better conjoined negotiation theory under risk can be developed and applied to an NDSS. In this process, the current and past research related to NDSS, game theoretic negotiation theory, negotiation analysis, psychological negotiation theory and prospect theory are reviewed. Further, realising that negotiation theory research is moving towards conjoined game theoretic psychological negotiation theory models, called Integrated Negotiation Theory (INT) in this paper. Two main INT models provided by Neale and Northcroft (1991) and Hausken (1997) are reviewed. After that, it is shown how Risk Factors (from Prospect Theory) can be applied to the Hausken (1997) model, called an Integrated Negotiation Theory (INT) model under the conditions of Risk (or INTR model). It is then recommended that this INTR model be used in the negotiation framework of an NDSS to improve the negotiated outcomes in a negotiation as an INTR model will provide insights from game theory, psychology and prospect theory that will be more powerful than just using one of these three theories by themselves.

\section{References}

Allais, M. 1953, Le comportement de l'homme rationel devant le risqué, critique des postulates et axioms de l'ecole americaine, Econometrica, 21, p. 503-546

Arrow, K.J. 1982, Risk perception in psychology and economics, Economic Inquiry, 20, p.1-9

Aumann, R. J. and Drèze, J. 1974, Cooperative Games with Coalition Structures, International Journal of Game Theory, 3, 217-237

Barberis, N., Huang, M. and Santos, T. 2001, Prospect Theory and Asset Prices, The Quarterly Journal of Economics, 116(1), February, p.1-53

Bazerman, M.H., Magliozzi, T., \& Neale, M.A. 1985, Integrative Bargaining in a Competitive Market, Organization Behavior and Human Performance, 34, 294-313

Bazerman, M.H., Baron, J. and Shonk, K. 2001, Enlarging the Societal Pie - A Cognitive Perspective, Harvard NOM Working Paper No. 02-17; Harvard Business School Working Paper No. 02-081, Harvard University, Cambridge

Bazerman, M.H. 2005, Conducting Influential Research: The Need for Prescriptive Implications, Academy of Management Review, 30, 25-31

Bazerman, M.H. and Chugh, D. 2004, Bounded Awareness: Focusing failures in negotiation, Working paper 04-062, Harvard University, Cambridge 
Bellucci, E. and Zeleznikow 2005, Developing Negotiation Decision Support Systems that support mediators: a case study of the Family_Winner system, Department of Information Systems, Victoria University, Melbourne

Berger, G., Kern, M. and Thompson, L. 2003, The Enlightened Negotiator: What is the Best Type of Interaction?, 16th Annual IACM Conference, Melbourne

Bendersky, C. and Curhan, J.R. 2003, Negotiator preference change: Motivational vs. Informational mechanisms for dynamic valuations, MIT Sloan school of management, Working paper 4306-03, MIT, Cambridge

Brams, S.J. 1990, Applying game theory to bargaining and arbitration, revised edition, Routledge, New York

Brams, S.J. and Taylor, A. 1996, Fair Division: From cake-cutting to dispute resolution, Cambridge University Press, Cambridge

Camerer, C.F. 1997, Progress in Behavioral Game Theory, Journal of Economic Perspectives, 11(4), Fall, 167-188

Carraro, C., Marchiori, C. and Sgobbi, A. 2005, Advances in negotiation theory: bargaining, coalitions and fairness, World Bank Policy Research Working paper 3642, June, New York

Cronin, M.A., Weingart, L.R., Cagan, J. and Vogel, C. 2002, How Conflict Results from Perceptual Gaps in the Shared Understanding of a Problem, IACM 15th Annual Conference, Utah

Curhan, J.R., Elfenbein, H.A. and Xu, H. 2006, What Do People Value When They Negotiate? Mapping the Domain of Subjective Value in Negotiation, MIT Sloan Research Paper No. 4544-05

Ellsberg, D. 1961, Risk, ambiguity and the Savage axioms, Quarterly Journal of Economics, 75, p. 643-669

Fiegenbaum, A. 1990, Prospect theory and the risk-return association: An empirical examination in 85 industries, Journal of Economic Behavior \& Organisation, 14(2), p. 187-203

Finberg, Y. 2002, Subjective reasoning in dynamic games, Research paper 1793, Stanford graduate school of business, Stanford

Harsyani, J.C. 1966, A general theory of rational behavior in game situations, Econometrica, 34 (3), July, 613-634

Harsyani, J.C. 1967, Games with incomplete information played by 'Bayesian' disputants, part I: The basic model, Management Science, 14(3), January, 159-182

Harsyani, J.C. 1968a, Games with incomplete information played by 'Bayesian' disputants, part II: Bayesian equilibrium points, Management Science, 14(5), January, 320-334

Harsyani, J.C. 1968b, Games with incomplete information played by 'Bayesian' disputants, part III: The basic probability distribution of the game, Management Science, 14 (7), March, 486-502

Harper, W. 1988, Decisions, games and equilibrium solutions. In Proceedings of the Biennial Meeting of the Philosophy of Science Association, vol. two: Symposia and invited papers, Philosophy of Science Association, University of Chicago Press, 344-362

Hausken, K. 1997, Game-theoretic and Behavioral Negotiation Theory, Group Decision and Negotiation, 6, 511-528

Heath, C. and A. Tversky 1991, Preferences and belief: ambiguity and competence in choice under uncertainty, Journal of Risk and Uncertainty, 4, p. 5-28

Kahnemann, D. and Tversky, A. 2000, Choices, Values and Frames, Cambridge University press, New York

Kim, Y.M., Bazerman, M.H. and Neale, M.A. 1990. The Role of Bargaining Zones and Agents: A Negotiation Simulation, Organizational Behavior Teaching Review, 14, 53-63

Korobin, R. and Guthrie, C. 2004, Heuristics and Biases at the Bargaining table, Marquette Law Review, 87, 795-808

Levy, J.S. 1997, Prospect Theory, Rational Choice and International Relations, International Studies Quarterly, 41(1), p. 87-112

Levy, M. and Levy H. 2002, Prospect Theory: Much Ado About Nothing?, Management Science, 48(10), October, p. 1334-1349

Luce, R.D. and Raiffa, H. 1957, Game and Decisions: Introduction and critical survey, John Wiley, New York

Mannix, E.A., Tinsley, C. and Bazerman, M.H. 1995, Negotiating Over Time: Impediments to Integrative Solutions, Organizational Behavior and Human Decision Processes, 62, 241-251 
McDermott, R. 1998, Risk taking in International Politics: prospect theory in American foreign policy, University of Michigan Press, 1998

Myerson, R. B. 1977, Graphs and Cooperation in Games, Mathematics of Operations Research, 2 , 225-229

Nash J.F. 1951, Non-cooperative games, Annals of Mathematics, 54, 286-295

Nash, J.F. 1950, The Bargaining Problem, Econometrica, 18, 155-162

Neale, M.A. and Bazerman, M.H. 1992, Negotiator Cognition and Rationality: A Behavioral Decision Theory Perspective, Organizational Behavior and Human Decision Processes, 51, 157-175

Neale, M.A and Northcroft, G.B 1991, Behavioral Negotiation Theory: A framework of dyadic bargaining, Research in Organizational Behavior, 13, 147-190

Osborne, M.J. and Rubinstein, A. 1990, Bargaining and Markets, Academic press, London

Raiffa, H., Richardson, J. and Metcalfe, D. 2002, Negotiation Analysis: The science and art of collaborative decision making, Harvard University Press, Massachusetts

Raiffa, H. 2005, The art and science of collaborative decision making, Harvard University Press, Massachusetts

Roth, A.E. 1983, Towards a theory of bargaining: An experimental study in economics, Science, 220, 13 June, 687-690

Roth, A.E. and Schoumaker, F. 1983, Expectations and Reputations in bargaining: An experimental study, American Economic Review, 73(3), June, 362-372

Roth, A.E. 1985, A note on risk aversion in a perfect equilibrium model of bargaining, Econometrica, $53,207-211$

Roth, A.E., Murnighan, J.K. and Schoumaker, F. 1988, The deadline effect in bargaining: Some experimental evidence, American Economic Review, 78(4), September, 806-823

Roth, A.E., Prasnikar, V., Okuno-Fujiwara, M. and Zamir, S. 1991, Bargaining and Market behavior in Jerusalem, Ljubljana, Pittsburgh and Tokyo: An experimental study, American Economic Review, 81(5), 1068-1095

Schmeidler, D. 1989, Subjective probability and expected utility without additivity, Econometrica, 57, p. $571-587$

Shapley, L. S. 1953, A Value for n-Person Games. In H. W. Kuhn and A. W. Tucker (eds.), Contributions to the Theory of Games II (Annals of Mathematics Studies 28), Princeton University Press, 307-317

Shapley, L. S. 1977, A Comparison of Power Indices and a Nonsymmetric Generalization, P-5872, Rand Corporation, Santa Monica

Shapley, L. S. and Shubik, M. 1954, A Method for Evaluating the Distribution of Power in a Committee System, American Political Science Review, 48, 787-792

Sebenius, J.K. and Lax, D. 2002, A 3-D view of negotiation theory and practice, IACM 15th Annual Conference, Utah

Sebenius, J.K. 2005, Negotiation Analysis: Between Decisions and Games. In W. Edwards, R. Miles and D. von Winterfeldt (eds.), Advances in Decision Analysis, Cambridge University Press, Cambridge

Siedsma, A. 2001, Arcadian Software, San Diego Business Journal, March, p. 12

Sondak, H. and Bazerman, M.H. 1991, Power Balance and the Rationality of Outcomes in Matching Markets, Organizational Behavior and Human Decision Processes, 50, 1-23

Tversky, A. 1969, The intransitivity of preferences, Psychology Review, 76, p.31-48

Tversky, A. and D. Kahneman 1986, Rational choice and the framing of decisions, The Journal of Business, 59(4), part 2, p.S251-S278

Tversky, A. and D. Kahneman 1991, Loss aversion in riskless choice: A reference dependent model, Quarterly Journal of Economics, 107(4), p. 1039-1061

Valley, K., Thompson, L.L., Gibbons, R. and Bazerman, M.H. 2002, How Communication Improves Efficiency in Bargaining Games, Games and Economic Behavior, 38, 127-155

Von Neumann, J. and O. Morgenstern 1944, Theory of Games and Economic Behavior, Princeton University Press, New Jersey

Wakker, P. and Tversky, A. 1993, An axiomatization of cumulative prospect theory, Journal of Risk and Uncertainty, 7(2), p. 147-175

Watkins, M. and Bazerman, M.H. 2003, Predictable Surprises, Harvard Business Review, March 
Weingart, L.R., Thompson, L.L., Bazerman, M.H. and Carroll, J.S. 1990, Tactical Behavior and Negotiation Outcomes, International Journal of Conflict Management, 1, 7-32

Weymark, J.A. 1981, Generalised Gini inequality indices, Mathematical Social Sciences, 1, p.409-430 Yaari, M.E 1987, The dual theory of choice under risk, Econometrica, 55, p.95-115 Young, H.P. 1992, Negotiation Analysis, University of Michigan Press, Ann Arbor 
